\title{
Two Approaches to Measure Trace Metals Fluxes at the Sediment-Water Interface: Sediment Porewater Profile and Benthic Incubation
}

\author{
Harmesa ${ }^{1, *}$ and A'an Johan Wahyudi ${ }^{1}$ \\ ${ }^{1}$ Research Center for Oceanography, Indonesian Institute of Sciences (LIPI), Pasir Putih Raya 1, Ancol Timur, Jakarta 14430, Indonesia \\ *Corresponding author: harmesa@lipi.go.id
}

\author{
KEYWORDS \\ Benthic fluxes \\ Overlying water \\ Porewater \\ Sediment \\ Trace metals
}

\begin{abstract}
The biogeochemical cycle of trace metals is very likely affected by the global change in the ocean, especially due to the increasing of sea surface temperature and acidity. Thus, assessing biogeochemical cycle of trace metals will beneficial in elucidating the potential impact of climate change as well as ocean acidification. The assessment of the biogeochemical cycle of trace metals can be performed by measuring trace metals fluxes crossing the sediment-water interface. The main challenge in this measurement is the difficulty of measuring metal concentrations at trace levels due to either physical factors or biological factors that can affect the total flux. Sediment porewater profile and in situ benthic incubation are the two most commonly used methods for measuring trace metals fluxes from sediment to the overlying water or vice versa. The coefficient of diffusion and gradient of concentration are the two most important values in the sediment porewater profile method, while the constant volume involved in the container during the experiment is an important part of the in situ benthic incubation method. The purpose of this review is to provide an overview of both measurement methods deeply and predict the challenges faced in its implementation in Indonesia.
\end{abstract}

(c) The Author(s) 2020. This article is distributed under a Creative Commons Attribution-ShareAlike 4.0 International license.

\section{INTRODUCTION}

Ocean warming and ocean acidification influence the sources and cycling of trace metals in the biogeochemical system globally (Hoffmann et al. 2012). The alterations of metals cycle in the marine biogeochemical can affect the water column, the bottom sediment, and the transfer processes at the sediment-water interface (Spagnoli et al. 2019). The sediment-water interface plays a vital role in the cycling, transferring, and preservation of materials in ecosystems. The fluxes of metals at this interface are not only influenced by the metal concentration gradient between overlying water and porewater, but also the content and composition of organic matter, bottom water oxygen concentration and penetration depth, activities of benthic organisms and bacteria, and external hydrological flow. Therefore, the estimation of fluxes of metals across the sediment-water interface is significant in assessing the biogeochemical cycling of metals, sedimentary environment, and the quality of the ecosystem (Ni et al. 2017).

The determination of the benthic flux of trace metals between the sediment and the overlying water is a difficult task, because of both the complexity of the pathways involved and the analytical difficulties in measuring metals' concentrations at the trace levels (Point et al. 2007). Some difficulties found in the calculation of flux as described by Berner (1976) are caused by an incorrect formulation and estimation of both gradients and diffusion coefficients; lack of an evaluation of the role of turbulent mixing at the sediment-water interface due to waves, currents, and bioturbation; lack of correction for the porewaters' deposi- tional burial; and lack of consideration of diffusion within the viscous-conductive sub-layer of the bottom water.

A number of methods have been developed to measure the benthic flux of trace metals, such as a sedimentporewater profile using gradient concentration (Cheng et al. 2019; Duan et al. 2019; Kalnejais et al. 2015; Ni et al. 2017; Santos-Echeandia et al. 2009), in situ benthic chamber (Frogner-Kockum et al. 2020; Han et al. 2016), moored sediment trap (Buesseler et al. 2007; Pohl et al. 2004), benthic boundary layer profile (Croot et al. 2019), the ${ }^{224} \mathrm{Th} /{ }^{228} \mathrm{Ra}$ disequilibrium method (Shi et al. 2018; Vieira et al. 2019), and isotopic mass balance data (Little et al. 2014). Gradient concentration and benthic chambers are the two most commonly used methods for measuring benthic fluxes of trace metals from the sediment to the overlying water, or vice versa (Viana et al. 2018). Both methods have many advantages, although each still has limitations. The sediment porewater method provides a relatively simple method for obtaining diffusive fluxes, reveals mechanisms of controlling flux, uses relatively efficient ship time and connects the observations of modern trace elements cycles to geological archives. Meanwhile, in situ benthic chamber incubation has an ability to measure the benthic fluxes (release or uptake) of trace elements, captures the influence of burrowing/irrigating animals in sediments, measures exchange rate without the need for knowledge of trace metals speciation or coefficients of diffusion, and uses spatial coverage of the seafloor widely compared with porewater profiles (Homoky et al. 2016).

Both of these methods have been widely developed globally, but they are very rarely used to measure fluxes of 
trace metals in Indonesian waters. The systematic study of trace metals flux in Indonesian waters is still limited; therefore, introducing these two common methods will likely initiate further study of the biogeochemical cycle of trace metals. This review aims to provide an overview of trace metals flux measurement methods that can be used in Indonesia and predict the challenges faced by Indonesian researchers in its implementation.

\section{STUDIES ON TRACE METALS IN INDONESIAN WATERS}

The source of trace metals in the ocean can come from many activities, either natural or anthropogenic (Kolibongso et al. 2017; Riyadi et al. 2012; Siregar et al. 2016). Geologically, the Indonesian archipelago has many active volcanoes that contribute to the entry of trace metals into the sea. The area of Indonesian waters is four times that of its land area and many human activities occur in the ocean, such as shipping, mining, etc. In addition, Indonesia is the fourth most populous country in the world, making it possible to produce both domestic waste and industrial waste on a large scale. From these activities, the entry of trace metals into the ocean is more intense. Therefore it will be interesting when we know the sources and the cycles of trace metals that occur in Indonesia's waters.

Measurement of trace metals fluxes at the sedimentwater interface is necessary to improve our understanding of the biogeochemical cycles of metals in the ocean. Several studies on trace metals have been carried out in Indonesian waters. Researchers in Indonesia have widely studied the distribution of trace metals in the sea, either in sediments or in the overlying water (Budianto and Lestari 2018; Kolibongso et al. 2017; Riyadi et al. 2012; Siregar et al. 2016; Widianarko et al. 2000). Observations of trace metal concentrations in the sediment have been carried out based on sediment coring, sediment fraction, spatial profile, and seasonal distribution. Budianto and Lestari (2018) have observed trace metal concentrations at a deep-sea floor of the Makassar Strait, at three layers of sediment, namely the surface layer $(0-5 \mathrm{~cm})$, middle layer $(45-55 \mathrm{~cm})$, and bottom layer. The detected trace metals were ordered as $\mathrm{Cd}$, $\mathrm{Pb}, \mathrm{Cu}, \mathrm{Ni}, \mathrm{Zn}$, and $\mathrm{Fe}$ with a range of values of $0.2-0.9,1.9-$ $12.5,7.7-65.2,28.8-144.8,62-101$, and $23658-47038 \mathrm{mg} / \mathrm{kg}$ dry weight, respectively, indicating that there is no enrichment to the minor enrichment of metals in the sediment. Meanwhile, an observation of trace metals conducted by Kolibongso et al. (2017) at the Karimata Strait found that trace metals originated from anthropogenic activities on land entering the waters through run-off and input from rivers. The same thing happened in Jakarta Bay, with the anthropogenic impact resulting in trace metals being found in higher concentrations at coastal sites compared with offshore sites (Riyadi et al. 2012). Based on seasonal variations, it was suggested by Siregar et al. (2016) that trace metal concentrations in Jakarta Bay were lower after the wet season and were higher at the end of the dry season.

Based on the observations and field studies, we can determine the source and the distribution of heavy metals. But that is not enough to understand the biogeochemical cycle of metals in the ocean. We need more information about the trace metals flux between the sediment and overlying water to explain the metals' movement when at sea. However, information about the fluxes of trace metals at the sediment-water interface in Indonesian waters is still minimal. In other countries, metals flux observations have been carried out, such as in China (Duan et al. 2019; Li et al. 2020; Liu et al. 2019; Ni et al. 2017), Sweden (FrognerKockum et al. 2020), France (Point et al. 2007; Rigaud et al. 2013), Italy (Emili et al. 2016; Zago et al. 2000), Spain (SantosEcheandia et al. 2009), Germany (Pohl et al. 2004), and the United States (Kalnejais et al. 2015). Through the positive or negative signs generated from the flux calculations, we could find out the direction of the metal movement in the sea. Observations of the metal flux at Daya Bay shows that the total mean fluxes of $\mathrm{Pb}\left(4.79 \mu \mathrm{mol} \mathrm{m} \mathrm{m}^{-1} \mu \mathrm{mol} \mathrm{m} \mathrm{d}^{-1}\right)$, $\mathrm{Cu}\left(1.63 \mu \mathrm{mol} \mathrm{m} \mathrm{d}^{-1}\right)$, Mn $\left(2619.13 \mu \mathrm{mol} \mathrm{m} \mathrm{m}^{2}\right)$, Ni $(2.54$ $\left.\mu \mathrm{mol} \mathrm{m} \mathrm{d}^{-1}\right), \mathrm{Cr}\left(6.27 \mu \mathrm{mol} \mathrm{m} \mathrm{d}^{-1}\right), \mathrm{Zn}\left(14.51 \mu \mathrm{mol} \mathrm{m}^{2} \mathrm{~d}^{-1}\right), \mathrm{Cd}$ $\left(0.057 \mu \mathrm{mol} \mathrm{m} \mathrm{d}^{-1}\right)$, and Fe $\left(872.27 \mu \mathrm{mol} \mathrm{m}^{2} \mathrm{~d}^{-1}\right)$ were positive (Ni et al. 2017). This positive sign also applies to all trace metal fluxes at the Changjiang Estuary (Duan et al. 2019). These findings indicate that the sediment served as the source for trace metals, causing the metals to be diffused from the sediment to the overlying water. In contrast, the sediment acts as a sink for $\mathrm{Cd}\left(-1.5 \mathrm{nmol} \mathrm{m} \mathrm{y}^{-1}\right)$ and $\mathrm{Cu}$ $\left.\left(-20 \mathrm{nmol} \mathrm{m} \mathrm{m}^{2}\right)^{-1}\right)$ in Jinzhou Bay (Li et al. 2020). Seasonally, most of the trace metals had higher flux value in spring than those in the summer (Duan et al. 2019). Regionally, most of the trace metals fluxes were higher in the hypoxic region as a consequence of oxygen depletion than those in the aerobic region in both seasons. Due to the important association with Fe-Mn oxi-hydroxides and organic matter, metals could be quickly remobilized as an effect of oxygen depletion (Duan et al. 2019; Emili et al. 2016).

Knowledge of the trace metal flux is an advanced topic after knowing its source and distribution. Through flux values, we can determine the direction of metals' movement in the ocean as a part of the biogeochemical cycling of trace metals, whether these metals mobilize into the sediment from the overlying water or vice versa. Furthermore, such a study will be useful in elucidating the potential impact of climate change and ocean acidification on either metal removal or metal uptake in the sediment. With the developed methods of trace metal measurements in the oceans globally, especially the sediment porewater profiles and in situ benthic incubation methods, it is expected to be able to optimize the measurements of trace metals fluxes in Indonesia. This study will become a frontier science in Indonesia in understanding trace metal biogeochemical cycles, especially the movement of metals between the sediment and overlying water.

\section{SEDIMENTS AS A SINK OR SOURCE OF TRACE METALS IN THE OCEANS}

Metals enter the ocean through several pathways (Henderson et al. 2007). In the first pathway, metals derived from the continents are transported through the atmosphere and deposited onto the sea surface. In the second, continental crusts eroded by chemical and physical processes are transported to the ocean margins by flow in rivers and groundwater. In the third, metals from the Earth's crust and mantle release into seawater through interaction with mid-ocean ridge basalts. And in the fourth pathway, metal sources can originate from marine sediments that can release and adsorb chemical species to and from seawater. The latter is interesting and worth being studied because sediment usually acts as a sink.

A portion of the metals released into the aquatic environment will be transferred to sediment through being adsorbed onto suspended matter and subsequently undergoing a sedimentation process (Zhu et al. 2016). Marine sediments are the main sink for trace metals that are caused by most metals having a high affinity with metal oxide, organic 
matter, or clay minerals that can lead to the occurrence of a metal accumulation process in the benthic sediment over time (Kang et al. 2009). The processes of organic matter degradation and early diagenesis in sediments affect the mobility of substances like trace metals. The redox conditions of the bottom water influence the sediment geochemistry, controlling the sediments to act as a sink or source of metals. In sediment, trace metals will be present in both the particulate phase and the dissolved phase, and these phases will interact not only with each other but also with the overlying water (Zhu et al. 2016). The distribution of trace metals between solid and liquid phases is influenced by changes in environmental conditions such as $\mathrm{pH}$, redox potential, and particle size, hence the sediment can act as a source of metals (Ololade et al. 2011) and result in the remobilization of metals from sediments to the overlying water (Duan et al. 2019; Wang and Wang 2017).

The atmosphere, continental run-off, oceanic crust, and marine sediment are ocean boundaries identified for the exchange of trace metals (Homoky et al. 2016). The sediment-bottom water exchange is a major process for controlling the chemical composition in the oceans (Berner 1976). Metal fluxes between sediments and the overlying water could be a significant component of the internal cycling of trace metals in the ocean. The overlying water is a major source for trace metals in sediments, although sediments could also be the source of trace metals when flowing metals are dominated by surface remobilization (Wang and Wang 2017).

Remobilization of trace metals in sediments is influenced by physicochemical conditions in the sediment and water column, and by the biogeochemical processes that occur during the early diagenesis of sediment, which includes biogeochemical reactions (e.g., sorption, precipitation, and dissolution), physical transport (e.g., diffusion and advection) or biological mechanisms (e.g., bioirrigation and bioturbation) (Duan et al. 2019; Rigaud et al. 2013). Biogeochemical reactions controlled by the microbial mineralization of organic matter can increase the concentration of trace metals in porewater and induce the transport mechanisms of trace metals to the overlying water (Rigaud et al. 2013). In addition, the concentration of oxygen in the water column affects the biogeochemical characteristics of the sediment, as well. In anoxic conditions of the bottom water, trace metal fluxes are given in a different direction. Both arsenic and manganese are diffused out from sediment to the overlying water, while copper is mobilized in the reverse direction (Riedel et al. 1997). The dissolved metals can be transported from sediments to the overlying water by diffusion or advection flow in permeable sediments driven by waves, tides, and pressure gradients from microtopography as physical factors (Kalnejais et al. 2015). Conversely, remobilization of trace metals caused by a biological transport mechanism is affected by bioturbation or bioirrigation of benthic organisms that could alter the speciation and distribution of trace metals in the sediment and thus encourage their release across the interface of sediment and water (He et al. 2019).

In shallow coastal sediments where deposition and bioturbation are significant, in situ flux measurement (i.e., in situ benthic chamber) can be a direct measurement of fluxes to and from the sediment. Meanwhile, in pelagic sediments-where bioturbation, current stirring, and deposition may be unimportant-we can use sediment porewater methods and simple Fick's first law of diffusion to measure the fluxes (Berner 1976).

\section{BENTHIC FLUX FORMULA}

The benthic flux of trace metals at the sediment-water interface can be defined as the mass of the metals flowing from overlying waters to the sediment, or vice versa, per unit of sediment surface area and per unit of time (Kamua et al. 2007; Zago et al. 2000). In a simple formula, benthic flux can be formulated as shown in Equation 1 (Zago et al. 2000):

$$
F=\frac{\Delta m}{A \cdot \Delta t}
$$

where $A$ indicates the surface area of the sediment-water interface and the unit of $A$ is given in $\mathrm{cm}^{2}$, while $\Delta t$ is contact time in an hour or day or year. The mass $(\Delta m)$ is related to the net concentration of trace metal species entering or exiting sediments in the benthic chamber. $\Delta m=\Delta C . V$, where $V$ as the volume of benthic chamber is given in $\mathrm{cm}^{3}$. Hence, the flux formula can be displayed in the form shown in Equation 2:

$$
F=\frac{\Delta C \cdot V}{A \cdot \Delta t}
$$

In the benthic chamber, the ratio between the volume of solution and surface area of sediment-water interface can be simplified as the high $(H)$ of the used chamber. As the equation $\frac{V}{A}=H$ substitutes to the formula (Equation 2), the benthic flux can also be written in the form shown in Equation 3 (Frogner-Kockum et al. 2020; Zago et al. 2000):

$$
F=\frac{\Delta C \cdot H}{\Delta t}
$$

where the unit of the benthic flux $(F)$ is expressed as $\mu \mathrm{g}$ $\mathrm{m}^{-2} \mathrm{~d}^{-1}, \mu \mathrm{mol} \mathrm{cm} \mathrm{c}^{-2} \mathrm{~h}^{-1}$, or pmol $\mathrm{cm}^{-2} \mathrm{~h}^{-1}$. The value of the benthic flux can be positive and negative depending on the direction of trace metal flow. A positive value indicates that metals are released from the sediment to the overlying water, whereas a negative value implies that metals sink from the overlying water to the sediment (Emili et al. 2016; Li et al. 2020; Point et al. 2007). The metal fluxes that have been determined by several experiments showed inconsistent directions, indicating sediments were the source or the sink of metals in different marine systems (Table 1).

\section{SEDIMENT POREWATER PROFILE}

Porewater is an important medium as the link between the sediment and the overlying water, and may reflect the material geochemical cycling in sediments by the characteristics of its element (Ni et al. 2017). The distribution and mobility of metals in porewater greatly influences the biogeochemical processes of the overall metals cycle and are responsible for the bioavailability of metals at the sedimentwater interface (Zhu et al. 2016). Dissolved metals that diffuse through the sediment-water interface to overlying water significantly influence the material cycling in the overlying water (Ni et al. 2017).

The reactions around the sediment-water interface are crucial to understanding trace metal cycling. The mobility of metals from sediments to porewaters and, ultimately, to the overlying water depend on the biodegradable organic matter due to oxygen conditions. Oxygen concentration in bottom waters affects the early diagenetic processes of organic matter biodegradation at the 
TABLE 1. Benthic fluxes of trace metals in several areas. (+) indicates trace metals flux out of sediment to the overlying water and (-) indicates flux into sediment from the overlying water.

\begin{tabular}{|c|c|c|c|c|c|c|c|c|c|c|}
\hline Location & Unit of flux & $\mathrm{Cd}$ & $\mathrm{Cu}$ & $\mathrm{Cr}$ & $\mathrm{Pb}$ & $\mathrm{Zn}$ & $\mathrm{Ni}$ & $\mathrm{Mn}$ & $\mathrm{Fe}$ & Reference \\
\hline Daya Bay, China & $\mu \mathrm{mol} \mathrm{m} \mathrm{d}^{-1}$ & +0.057 & +1.63 & +6.27 & +4.79 & +14.51 & +2.54 & +2619.13 & +872.27 & Ni et al. (2017) \\
\hline Jinzhou Bay, China & $\mathrm{nmol} \mathrm{m} \mathrm{m}^{2} \mathrm{y}^{-1}$ & -2.5 & -20 & & +2.6 & +371 & +22 & & & Li et al. (2020) \\
\hline $\begin{array}{l}\text { Taranto's Mart Piccolo, Italy } \\
\text { (st 1E) }\end{array}$ & $\mu g \mathrm{~m}^{2} \mathrm{~d}^{-1}$ & 0 & -55 & -30 & 24 & -26 & +22 & +260 & +219 & Emili et al. (2016) \\
\hline $\begin{array}{l}\text { Taranto's Mart Piccolo, Italy } \\
\text { (st 1I) }\end{array}$ & $\mu g \mathrm{~m}^{2} \mathrm{~d}^{-1}$ & -5 & +444 & -62 & +55 & +453 & +19 & +274 & +487 & Emili et al. (2016) \\
\hline Vigo Ria, Spain (Mussel rafts st) & $\mathrm{nmol} \mathrm{m} \mathrm{m}^{2} \mathrm{y}^{-1}$ & & -0.02 & & -0.02 & -0.37 & +0.18 & & & Santos-Echeandia et al. (2009) \\
\hline Vigo Ria, Spain (Ria axis st) & $\mathrm{nmol} \mathrm{m} \mathrm{m}^{2} \mathrm{y}^{-1}$ & & +0.18 & & -0.01 & +0.90 & +1.59 & & & Santos-Echeandia et al. (2009) \\
\hline Hingham Bay, USA (Summer) & $\mu \mathrm{mol} \mathrm{m} \mathrm{y}^{-1}$ & & -46 & & -4 & & & +56 & +240 & Kalnejais et al. (2015) \\
\hline
\end{tabular}

sediment level. As a result of oxygen depletion, labile trace metals associated with organic particles are released into sediment porewaters. The higher the dissolved metal concentration in the porewater, the higher the metal release to the overlying water. In addition, the transportation of the dynamic metals is also controlled by the chemical form in which the metals are present in the sediment matrix, such as $\mathrm{Fe} / \mathrm{Mn}$ mineral phases or metal sulfide phases. Dissolved trace metals that release to the porewater move upward partially to the overlying water, and the others are scavenged and removed from porewater by manganese and iron (hydr)oxides through the coprecipitation process. Contrarily, when Fe/Mn mineral phases pass through a reducing process that may be catalyzed by the deposition of organic matter, they can release trace metals back to porewaters. In anoxic conditions, trace metals from both the overlying water and porewaters are removed through the precipitation process of metal sulfides which are poorly soluble (or insoluble) and tend to be trapped in the sediment. However, the oxidation process of metal sulfides can release dissolved trace metals back into the porewater (Duan et al. 2019; Emili et al. 2016; Kalnejais et al. 2015; Wang and Wang 2017).

Sediment porewater comprising from $50 \%$ to more than $90 \%$ of the sediment by volume may contain the products and reactants of early diagenetic reactions that confiscate, recycle, and release dissolved trace (Homoky et al. 2016). Fluxes of dissolved metals between porewater sediment and overlying bottom water are driven by different concentrations in chemical composition on both sides (Berner 1976). The concentration gradient at the sedimentwater interface is used to calculate the outward flux from the sediment or inward flux to the sediment (Liu et al. 2019). When metal concentrations in the uppermost porewater is higher compared with the dissolved metal concentrations in bottom seawater, it indicates that the benthic flux of metals will be released by sediments to overlying waters ( $\mathrm{Li}$ et al. 2020; Zhu et al. 2016).

Trace metals benthic fluxes are quantified in a onedimensional diagenetic transport-reaction model as proposed by Boudreau in Rigaud et al. (2013) and the formula is assumed as steady-state (Equation 4; Li et al. 2020).

$$
\left(\frac{\partial \varphi C_{p w}}{\partial t}\right)_{x}=\frac{\partial}{\partial x}\left(\varphi\left(D_{s}+D_{B}\right) \frac{\partial C_{p w}}{\partial x}\right)+v \frac{\partial C}{\partial x}+\varphi \alpha\left(C_{o}-C_{p w}\right)+R=0
$$

where $C_{p w}$ is metal concentration in porewater, $C_{o}$ is dissolved metal concentration in bottom seawater, $x$ and $t$ represent the depth and time, respectively, $\varphi$ is porosity, $D_{s}$ is coefficient of molecular diffusion in the porewater, $D_{B}$ is biodiffusivity associated with the sediment, $v$ is advective flow velocity in porewater, $\alpha$ is the bioirrigation rate coefficient, and $R$ is the net rate of reaction corresponding to the production or consumption reaction of the species in the porewater.

The benthic flux varies widely because it is influenced both temporarily and spatially by many factors. In Equation 4 , several different types of flux are associated with governing the metals exchange process between the sediment and the overlying water.

First, the diffusive flux corresponds to the natural diffusion of trace metals between porewater and the overlying water that is largely influenced by the concentration gradient, with a range and direction depending on the depleted or enriched fraction. The continuous process of species migration that crosses the sediment-water interface includes molecular diffusion or ionic diffusion. Molecular diffusion describes the migration of neutral species, whereas ionic diffusion refers to migration of charged species that interact electrostatically (Black et al. 2008; Li et al. 2020).

Second, bioturbation is a result of biological activities living in biogenic structures buried in the sediment. The transport of solutes and solids occurs in subsurface sediments through benthic organisms' feeding and movement. This process affects the total flux by around $4-5 \%$ (Li et al. 2020). The biodiffusivity $\left(D_{B}\right)$ depending on sedimentation rate $(\omega)$ is calculated by the formula (Equation 5):

$$
\log _{10}\left(D_{B}\right)=1.63-0.05 \log _{10} \omega
$$

Third, the advective flux that represents a flow of water or sediment corresponds to the exchange of metals between the sediment and the overlying water and contributes to the transportation of many solutes at a greater distance. Advection can be caused by burial, compaction, and external hydrological flow driven by waves, tides, or pressure gradients. It is an important process in metal transport that is related to the diffusion process. The solutes that diffuse out of sediments are advected away into the overlying water. The advection process prevents metal accumulation at the sediment-water interface caused by the diffusion process and facilitates the higher diffusive fluxes from or to sediments (forward or reverse direction) by maintaining a large concentration gradient across the sediment-water interface (Black et al. 2008).

Fourth, the bioirrigation effect originates from tubedwelling animals living below the oxic layer in surface sediments. These tubes are used as irrigation of oxygenated wa- 
ter from the overlying water to the sediments, aside from being a place for the transport of food, metabolic wastes, gametes, and environmental stimuli. The bioirrigation rate coefficient $(\alpha)$ can be estimated from the size and density of the tubes as well as the solute gradients around the tube. Irrigation of diffusivity can significantly influence the transport of solutes in sediments and induces an increase of the total benthic flux (Black et al. 2008; Li et al. 2020).

Equation 4 can be simplified with the proposal of several approaches. When the Peclet numbers calculated in the cores are low (below 0.1), the advection resulting from the compaction of sediments and burials can be negligible compared with diffusion (Li et al. 2020). The recurrent anoxic conditions in the overlying water totally affects the benthic faunal density in the sediments. When the colonization of benthic organisms is prevented, the value of $D_{B}$ is close to zero, consequently, the effects of biodiffusion and bioirrigation are neglected in the total fluxes (Rigaud et al. 2013).

In the simplest form, the benthic flux of trace metals in the sediment porewater profile is based on the concentration gradient following Fick's first law of diffusion (Equation 6; Homoky et al. 2016):

$$
J_{i}=-\varphi D_{i}^{s e d}\left(\frac{\partial C_{i}}{\partial z}\right)
$$

where $J_{i}$ is the flux of trace metal $i, \partial C_{i}$ is metals change in concentration, $\partial z$ is a range in depth, $D_{i}^{\text {sed }}$ is an effective diffusion coefficient and $\varphi$ is the specific porosity of sediments. The effective diffusion coefficients $\left(D_{i}^{\text {sed }}\right)$ are calculated for specific sediments that are related to diffusion coefficients in seawater $\left(D_{i}^{S W}\right)$ and their tortuosity $(\theta$; Equation 7). The diffusion coefficient in seawater is influenced by temperature and mass effects, which increase the diffusion rates with increasing temperature and decreasing mass of the solute.

$$
D_{i}^{\text {sed }}=\frac{D_{i}^{S W}}{\theta^{2}}
$$

Tortuosity $(\theta)$ is well-approximated from porosity of sediments $(\varphi)$, both obtained as a fraction of porewater volume and decrease rapidly with increasing depth (Equations 8 and 9).

$$
\theta^{2}=1-\ln \left(\varphi^{2}\right)
$$

$$
\varphi=\frac{\text { volume of porewater }}{\text { volume of porewater }+ \text { volume of solid sediment }}
$$

If the flux calculation is only based on the diffusion process, as followed in Fick's first law, then the accuracy of the concentration-depth gradient value and diffusion coefficient is absolutely required. Diffusive fluxes methods need particular attention to obtain their representativity in environments with high spatial and temporal variability, which can be determined using microscales in situ probes (Point et al. 2007).

The dissolved metals fluxes become more meaningful when compared with the water column inventories to know the benthic fluxes' contribution to the current standing stock of dissolved metals, by following the formula shown in Equation 10.

$$
\begin{aligned}
& \text { inventory of metals in the water column } \\
& \begin{aligned}
= & \text { water column concentration }\left(\mathrm{mmol} \mathrm{L}^{-1}\right) \\
& \times \text { mean depth }(\mathrm{m}) \\
& \times \text { area }\left(\mathrm{m}^{2}\right)
\end{aligned}
\end{aligned}
$$

Another perspective is to compare the flux with the metals inventory in the top $2 \mathrm{~cm}$ of the sediments (Equation 11).

$$
\text { metal inventory }=(1-\varphi) \times p_{s} \times\left([\text { metal }]_{s e d}-[\text { metal }]_{b g}\right) \times 2
$$

where $\varphi$ is porosity, $p_{s}$ is sediment density, [metal $]_{s e d}$ and [metal $]_{b g}$ are metal concentration in surface sediment and background, respectively. However, $2 \mathrm{~cm}$ was chosen to represent the surface sediments and only give a rough estimate for how long the benthic flux for each metal will persist as a source to the overlying water. In reality, the sediment can be mixed through biological activities or physical processes at lower depths, hence they undergo a process of self-cleaning, as well (Li et al. 2020).

The gradient of trace metal concentrations between the porewater and the overlying water may be obtained by analyzing samples of near-bed seawater and porewater extracted from the surface sediments. Several methods that have been used to collect porewater include using in situ dialyzers inserted into the sediment, squeezing undisturbed sediment cores, and centrifugation of sediment cores at a very high speed under inert atmosphere and controlled temperature (Ciceri et al. 1992).

The sediment porewater profile method has been used by Santos-Echeandia et al. (2009) to measure the trace metals flux in Vigo Ria, Spain, which is an estuarine-coastal system. The detected flux value was different for each metal, 0.03-0.24 nmol cm $\mathrm{n}^{-2}$ for Co, (-0.02)-1.11 nmol cm $\mathrm{n}^{-2} \mathrm{y}^{-1}$ for $\mathrm{Cu}, 0.16-1.70 \mathrm{nmol} \mathrm{cm}{ }^{-2} \mathrm{y}^{-1}$ for $\mathrm{Ni},(-0.14)-0.03 \mathrm{nmol}$ $\mathrm{cm}^{-2} \mathrm{y}^{-1}$ for $\mathrm{Pb}, 1.48-4.35 \mathrm{nmol} \mathrm{cm} \mathrm{cm}^{-2}$ for $\mathrm{V}$, and (-0.37)$0.90 \mathrm{nmol} \mathrm{cm} \mathrm{cm}^{-2} \mathrm{y}^{-1}$ for $\mathrm{Zn}$. Their results showed that the mobility of each metal has different directions, hence the sediment acts as a sink and a source of dissolved trace metals. Redox geochemistry and diagenesis are processes that control the benthic fluxes in Vigo Ria (Santos-Echeandia et al. 2009). Other locations in which the sediment porewater profile method has been used are Berre Lagoon, France (Rigaud et al. 2013), Massachusetts Bay and Hingham Bay, United States (Kalnejais et al. 2015), and Changjiang Estuary (Duan et al. 2019), Jinzhou Bay (Li et al. 2020), Bohai Bay (Liu et al. 2019), and Daya Bay in China (Ni et al. 2017).

\section{IN SITU BENTHIC INCUBATION}

The difference between the diffusive methods and benthic chamber methods used to determine the fluxes of trace metals could be influenced by benthic macrofauna activity and advective factors (Point et al. 2007). Benthic organisms' activities were found by He et al. (2019) to influence the exchange of dissolved metals in sediment in different ways, such as re-suspension of the sediment particle by the organisms' movement, ingestion, and biological sedimentation or occurring bioturbation/bioirrigation process (discrete animal burrows). By capturing a larger surface area of the seafloor, the benthic chambers method may integrate the patchy influence of their activities.

In situ benthic incubation is a method that is designed involving the deployment of benthic chambers on the sediment to trap seawater in contact with the seafloor. This 
method can provide a direct measurement of net metals exchange by controlling the isolated water volume over time. Consumption or release of water volume that can be monitored over time affects the measured metal concentration. A decrease in concentration occurs due to the consumption of water volume, whereas an increase in concentration occurs due to the volume of water released (Viana et al. 2018). Important points in this method are the guaranteed cleanliness of the instrument and the required sample volume at discrete time intervals for subsequent shipboard or laboratory analyses (Homoky et al. 2016). The collected data of metal concentrations versus time can be used to determine a flux rate.

Spagnoli et al. (2019) have developed two devices of benthic chambers to measure the dissolved chemical fluxes between the sediment and the overlying water. The development of these devices aimed to assess both the biogeochemical cycle and the change in benthic-pelagic coupling in the aquatic environment due to human activities. These chambers, named the Amerigo Lander and the Automatic Benthic Chamber (CBA), were developed for different depths. The Amerigo Lander can be deployed in both shallow water and deep bottom of water, up to $6000 \mathrm{~m}$, whereas the CBA can be operated for shallow water and on the continental shelf up to $200 \mathrm{~m}$. In shallow waters, the benthic chambers are handled by divers, whereas in deeper water, the chambers are mounted on the benthic lander (Spagnoli et al. 2019).

The trace metals flux from sediments into overlying water during the incubation experiments are calculated using Equation 12 (Han et al. 2016).

$$
J_{i}=\frac{\sum_{i=1}^{n}\left(V_{i-1} x\left(C_{i}-C_{i-1}\right)\right)}{A x t_{n}}
$$

where $J_{i}$ is the flux of trace metals across the sedimentwater interface during the time of incubation experiments $\left(t_{n}\right), n$ is the sampling number, $A$ is the surface area of sediment in the chamber, $C_{i}$ is trace metals concentration at time $t_{i}, C_{i-1}$ and $V_{i-1}$ are trace metals concentration and the volume of overlying water at time $t_{i-1}$, respectively.

During sampling, there is a possibility that water will flow from outside into the chamber to replace the volume collected in the syringe and cause dilution. The final concentration of the sample must be corrected depending on the number of syringes employed. This correction is performed using a reference syringe that is placed simultaneously outside the chamber (Point et al. 2007). The subsequent formula used by Point et al. (2007) to obtain the concentration corrected from the dilution effect $\left(C_{c}\right)$ is written as (Equation 13):

$$
C_{c}=\frac{\left(C_{f}\left(V_{c}-V_{s}\right)+C_{r e f} V_{s}\right)}{V_{c}}
$$

where $C_{f}$ and $C_{r e f}$ are the sample concentration collected at the end of the experiment (in the syringe) and the water concentration collected simultaneously outside the chamber, respectively, while $V_{c}$ and $V_{s}$ are the water volume enclosed in the chamber and the total volume of the sample collected at the end of the experiment, respectively.

The real volume of each chamber can be measured using the solution of a non-reactive solute, such as $\mathrm{CsCl}, \mathrm{BrCl}$, or deionized water, following Equation 14. A known concentration of tracer is injected into the chamber and should be constant during the experiment in the chamber. If this does not happen, the possible reason is that the benthic chamber is not well placed on the bottom, there are leaks, or an occurring irrigation process is underway in the bottom sediment (Spagnoli et al. 2019).

$$
V_{r}=\frac{C_{t} x V_{t}}{C_{r}}
$$

where $V_{r}$ and $V_{t}$ are the real volume of the benthic chamber and the tracer volume injected into the chamber, respectively, while $C_{r}$ and $C_{t}$ are the tracer concentration both in the chamber after injection and in the syringe, respectively.

The trace metal flux calculation relates to the change in solute concentrations in the enclosed overlying water, which is affected by the immobilization of dissolved metal into or out of the sediment. The calculation is based on several assumptions: (a) the condition during the incubation period is steady-state with respect to solute exchange, (b) the biogeochemical process rate in the overlying water could be ignored compared with that within the sediment, (c) as compared to natural conditions, the hydrodynamic processes in the chamber do not alter solute exchange across the sediment-water interface, and (d) the sampling area is representative for a larger seafloor area (Viollier et al. 2003). However, under various conditions, some of these assumptions may not be true.

The in situ benthic incubation method has been used by Point et al. (2007) to measure the trace metals flux in Thau Lagoon, which is located in the Southeast of France along the Mediterranean Sea coast, with the following results: (-0.35)-4.76 $\mu \mathrm{mol} \mathrm{m}{ }^{-2} \mathrm{day}^{-1}$ for Co, (-11.4)-30.8 $\mu \mathrm{mol}$ $\mathrm{m}^{-2}$ day $^{-1}$ for $\mathrm{Cu},(-97)-246 \mu \mathrm{mol} \mathrm{m}^{-2}$ day $^{-1}$ for $\mathrm{Mn},(-0.5)-$ $4.2 \mu \mathrm{mol} \mathrm{m}{ }^{-2} \mathrm{day}^{-1}$ for $\mathrm{Pb},(-7.5)-20.4 \mu \mathrm{mol} \mathrm{m}^{-2}$ day $^{-1}$ for $\mathrm{V}$, and (-130) $-286 \mu \mathrm{mol} \mathrm{m}{ }^{-2}$ day $^{-1}$ for Cd. The detected flux values ranged from negative to positive values for all metals, which indicates that the sediment at several sampling points acted like a sink, and others acted as a source of dissolved trace metals. All metals either migrate to the sediment or release to the overlying water depending on the sampling location. Through this method, it can be seen that spatial and temporal variability of these benthic fluxes are influenced by macrophytic and macrofaunal distributions in Thau Lagoon (Point et al. 2007). Other locations that apply the benthic incubation method to measure trace metal fluxes are in the Estuary of Ångermanälven River in Northeastern Sweden (Frogner-Kockum et al. 2020), in Taranto's Mar Piccolo, Italy (Emili et al. 2016), and in the Northern Adriatic Sea in front of the River Po outflow, Italy (Zago et al. 2000).

\section{CHALLENGES IN TRACE METALS RESEARCH IN INDONESIA}

Theoretically, the change of temperature and seawater $\mathrm{pH}$ greatly affects the solubility of metals in the sea. But the changing of both ocean warming and ocean acidity affect trace metal biogeochemistry, which is more complex than the usual solubility of metals (Hoffmann et al. 2012). This must be a concern of Indonesian researchers as the Indonesian seas become an important part of the world ocean systems due to its location between the Pacific Ocean and the Indian Ocean. Our understanding of the biogeochemistry cycles of trace metals in the ocean can also aid in contributing more knowledge regarding the effects of climate change, as it relates to the 13th Sustainable Development Goal (SDG) set out by the United Nations. 
The challenges of ocean trace metals research in Indonesia includes both technical measurement and resource limitations. The resource limitations include the human resources skill, infrastructure for field sampling and analysis, and funding sources.

Analytical measurement of the trace metals flux across the sediment-water interface is influenced by several factors that occur at the bottom of the water. In terms of biological factors, evaluation of the bioturbation/bioirrigation effect is needed, whether it enhances the total flux or not in the calculation. Meanwhile, species migration, burial, compaction, or external hydrological flow will be a challenge as physical factors. These difficulties are the challenges of measuring the trace metal fluxes faced by researchers globally, including by researchers in Indonesia. A number of methods have been developed to measure the flux of trace metals. The sediment porewater profile and benthic incubation methods are two that are widely used to measure the trace metals flux. Each method has many advantages but still has limitations that pose challenges in technical measurement, as shown in Table 2.

Challenges in measurement can be solved using the developed methods. Sediment porewater profile and incubation chamber are two separate methods that have been developed by ignoring some physical and biological factors described above. Still, they reflect the results of trace metals fluxes. The sediment porewater profile is used by paying close attention to the values of the coefficient of diffusion and gradient of concentration that is representative of the "dissolved" pool trace metal. Therefore, the main challenge of this method is carefulness in porewater sampling accompanied by the use of sampling and storage equipment that is guaranteed to be clean. In contrast, the use of the in situ benthic incubation method pays attention to the constant volume involved in the container during the experiment. Technically, the main challenge of this method is the difficulty of landing the benthic chambers on the seafloor, obtaining a seafloor coverage that is representative of the area, and keeping the water volume constant. To overcome this problem, the development of benthic chambers and landers needs to be carried out, both for deep water and shallow waters, as was conducted by Spagnoli et al. (2019) and Roth et al. (2019).

Each method is independent and is usually used separately. However, there are several studies that use both methods at the same time to study the trace metal flux, such as observations both in the Mar Piccolo of Taranto, Italy (Emili et al. 2016), and in Ansedonia Bay, Italy (Ciceri et al. 1992). The results showed that the benthic fluxes by the incubation chamber were higher than diffusive fluxes, potentially due to a strong bioturbation/bioirrigation process in the sediment (Emili et al. 2016; Point et al. 2007). Therefore, both sediment porewater profile and in situ benthic incubation can be applied in Indonesia more easily than other methods. Although these two methods are standalone methods, it is better if both are utilized simultaneously for a more in-depth study.

The availability of sufficiently clean equipment is the main challenge in measuring metal flux in trace levels. The use of clean laboratories, high-purity water, and ultraclean laboratory materials are vital to minimize the risk of contamination (Sabé and Rauret 2004), as well as for the equipment used in sampling or storage. With the government or national agency's support in terms of the availability of research equipment, researchers in Indonesia can maximize the research in this field and therefore play an active role in implementing one of the SDGs goals.

The lack of researchers who can measure trace metals fluxes is another challenge to its implementation in Indonesia, besides the scarcity of marine geochemistry research in Indonesia. The ability in analytical procedures is necessary to measure metals in trace levels. The measurement of metal concentrations at the trace levels needs careful analytical methods in sampling, pre-treatment, and storage to minimize any analytical errors. Collaborative research may be one way to overcome this problem, not only between researchers in Indonesia but also with foreign researchers.

All challenges, including difficulties in measuring, availability of tools, and competent human resources, can be overcome with good collaboration between the government, researchers, and funding bodies. A good understanding of measurement is not enough if it is not equipped with the availability of suitable equipment. We are also expecting that the government and funders play an essential role managing these needs. This task consists of providing the tools, and overcoming the lack of competent researchers in this field. In addition to paving the way to collaboration with foreign researchers, researchers are given broad opportunities and are encouraged to continue their education especially in this field. By having more experts, Indonesia will be able to understand global problems, such as the global climate change effect from the viewpoint of

TABLE 2. Advantages, limitations, and challenges of sediment porewater profile and in situ benthic incubation measurements (Hammond et al. 2004; Homoky et al. 2016; Roth et al. 2019).

\begin{tabular}{|c|c|c|c|}
\hline Method & Advantages & Limitations & Challenges \\
\hline Sediment porewater profile & $\begin{array}{l}\text { Provides a relatively simple method for } \\
\text { obtaining diffusive flux, reveals } \\
\text { mechanisms of controlling flux, takes a } \\
\text { relatively efficient ship time by shorter } \\
\text { duration of stations (by using sediment } \\
\text { coring), and connects the observations } \\
\text { of modern trace elements cycles to } \\
\text { geological archives. }\end{array}$ & $\begin{array}{l}\text { The depth profile can be affected by the } \\
\text { heterogeneity of the seafloor, the } \\
\text { assumption that steady-state porewater } \\
\text { may not be valid due to dynamic } \\
\text { macrofauna activity or seasonal } \\
\text { sedimentation not captured by this method, } \\
\text { and some artifacts accumulating in the core } \\
\text { collection may affect the flux result. }\end{array}$ & $\begin{array}{l}\text { Technically, this method } \\
\text { presents a challenge in } \\
\text { taking porewater } \\
\text { sampling that is } \\
\text { sensitive to changes in } \\
\text { ex-situ redox, } \\
\text { temperature, and } \\
\text { pressure. }\end{array}$ \\
\hline In situ benthic incubation & $\begin{array}{l}\text { Has an ability to measure benthic flux } \\
\text { (release or uptake) of trace elements, } \\
\text { uses a wider spatial coverage of the } \\
\text { seafloor than the porewater profile that } \\
\text { captures the influence of } \\
\text { burrowing/irrigating animals in the } \\
\text { sediment, and measures the rate of } \\
\text { solute exchange without needing } \\
\text { knowledge of trace element speciation } \\
\text { or diffusion coefficient. }\end{array}$ & $\begin{array}{l}\text { Low coverage of incubation may not } \\
\text { represent the global seafloor environment, } \\
\text { the incubation times that may not be } \\
\text { suitable for some trace metal exchange } \\
\text { rates, and it requires a longer time and } \\
\text { special skills to land the benthic chambers. }\end{array}$ & $\begin{array}{l}\text { The main challenge of } \\
\text { this method is to land } \\
\text { the benthic chambers } \\
\text { on the seafloor and } \\
\text { maintain a constant } \\
\text { volume of the water in } \\
\text { the chamber. }\end{array}$ \\
\hline
\end{tabular}


the biogeochemical cycling of trace metals, primarily due to increasing sea surface temperatures and ocean acidity.

\section{CONCLUSION}

The measurement of trace metals fluxes crossing the sediment-water interface is significant to assess the biogeochemical cycling of metals that are associated with the effects of global change in the ocean. Several different types of flux are associated with governing the metals exchange process between the sediment and the overlying water. But under certain conditions, some of them can be neglected, resulting in measurements that can be made more easily, especially by applying the principle of the sediment pore water profile and benthic incubation chamber. Both of these methods have been developed extensively, and thus we can apply them in Indonesia by developing them according to our needs. By looking at some of the challenges faced by Indonesian researchers and possible solutions in measuring trace metals fluxes, we are optimistic that we can initiate observation related to this biogeochemical cycling by utilizing one of these two methods. Good collaboration between the government, researchers, and funding bodies from either national agencies or foreign institutions will encourage this research to be more advanced in Indonesia.

\section{AUTHORS' CONTRIBUTIONS}

$\mathrm{H}$ was the primary contributor in writing the first draft of the manuscript. AJW supervised $\mathrm{H}$ in designing and writing the manuscript. All authors provided suggestions and comments, conducted proofreading, and approved the final version of the manuscript.

\section{COMPETING INTERESTS}

The authors declare no competing interest.

\section{REFERENCES}

Berner RA. 1976. The Benthic boundary layer from the viewpoint of a geochemist. In: McCave I, editor. The Benthic boundary layer. Boston: Springer US. p. 33-55. doi:10.1007/978-1-4615-8747-7_3.

Black FJ, Gallon C, Flegal AR. 2008. Sediment retention and release. In: Jørgensen SE, Fath BD, editors. Encyclopedia of ecology. Oxford: Academic Press. p. 3172-3181. doi:10.1016/B978-008045405-4.00294-9.

Budianto F, Lestari. 2018. Trace metal in sediment from a deep-sea floor of Makassar Strait. IOP Conf Ser: Earth Environ Sci. 118(1):12057. doi:10.1088/1755-1315/118/1/ 012057.

Buesseler KO, Antia AN, Chen M, Fowler SW, Gardner WD, Gustafsson O, Harada K, Michaels AF, van der Loeff MR, Sarin M, Steinberg DK, Trull T. 2007. An assessment of the use of sediment traps for estimating upper ocean particle fluxes. J Mar Res. 65(3):345-416. doi:10.1357/ 002224007781567621.

Cheng D, Song J, Zhao X, Wang S, Lin Q, Peng J, Su P, Deng W. 2019. Effects of chironomid larvae and Limnodrilus hoffmeisteri bioturbation on the distribution and flux of chromium at the sediment-water interface. J Environ Manage. 245:151-159. doi:10.1016/j.jenvman.2019.0 5.083.

Ciceri G, Maran C, Martinotti W, Queirazza G. 1992. Geochemical cycling of heavy metals in a marine coastal area: benthic flux determination from pore water profiles and in situ measurements using benthic chambers. Hydrobiologia. 235-236(1):501-517. doi:10.1007/BF0002 6238.

Croot PL, Heller MI, Wuttig K. 2019. Redox processes impacting the flux of Iron(II) from shelf sediments to the OMZ along the Peruvian shelf. ACS Earth Space Chem. 3(4):537-549. doi:10.1021/acsearthspacechem.8b0020 3.

Duan L, Song J, Liang X, Yin M, Yuan H, Li X, Ren C, Zhou B, Kang X, Yin X. 2019. Dynamics and diagenesis of trace metals in sediments of the Changjiang Estuary. Sci Total Environ. 675:247-259. doi:10.1016/j.scitotenv.2019.0 4.190 .

Emili A, Acquavita A, Covelli S, Spada L, Di Leo A, Giandomenico S, Cardellicchio N. 2016. Mobility of heavy metals from polluted sediments of a semienclosed basin: in situ benthic chamber experiments in Taranto's Mar Piccolo (Ionian Sea, Southern Italy). Environ Sci Pollut Res. 23(13):12582-12595. doi:10.1007/s1 1356-015-5281-1.

Frogner-Kockum P, Kononets M, Apler A, Hall POJ, Snowball I. 2020. Less metal fluxes than expected from fibrous marine sediments. Mar Pollut Bull. 150:110750. doi:10.1016/j.marpolbul.2019.110750.

Hammond DE, Cummins KM, McManus J, Berelson WM, Smith G, Spagnoli F. 2004. Methods for measuring benthic nutrient flux on the California Margin: Comparing shipboard core incubations to in situ lander results. Limnol Oceanogr Methods. 2(6):146-159. doi: 10.4319/lom.2004.2.146.

Han J, Ro HM, Cho KH, Kim KW. 2016. Fluxes of nutrients and trace metals across the sediment-water interface controlled by sediment-capping agents: bentonite and sand. Environ Monit Assess. 188(10):1-11. doi:10.1007/s1 0661-016-5583- $x$

He Y, Men B, Yang X, Li Y, Xu H, Wang D. 2019. Relationship between heavy metals and dissolved organic matter released from sediment by bioturbation/bioirrigation. J Environ Sci. 75:216-223. doi:10.1016/j.jes.2018.03.031.

Henderson GM, Anderson RF, Adkins J, Anderson P, Boyle EA, Cutter G, Zhang J. 2007. GEOTRACES - An international study of the global marine biogeochemical cycles of trace elements and their isotopes. Geochemistry. 67(2):85-131. doi:10.1016/j.chemer.2007.02.001.

Hoffmann LJ, Breitbarth E, Boyd PW, Hunter KA. 2012. Influence of ocean warming and acidification on trace metal biogeochemistry. Mar Ecol Prog Ser. 470:191-205. doi:10.3354/meps10082.

Homoky WB, Weber T, Berelson WM, Conway TM, Henderson GM, Van Hulten M, Jeandel C, Severmann S, Tagliabue A. 2016. Quantifying trace element and isotope fluxes at the ocean-sediment boundary: a review. Philos Trans R Soc. A. 374(2081):20160246. doi:10.1098/rs ta.2016.0246.

Kalnejais LH, Martin WR, Bothner MH. 2015. Porewater dynamics of silver, lead and copper in coastal sediments and implications for benthic metal fluxes. Sci Total Environ. 517:178-194. doi:10.1016/j.scitotenv.2015.02.011.

Kamua JN, Dehairs F, Marteen L, Kazunga J. 2007. Sedimentwater exchange of selected heavy metals at the backwaters of Makupa Creek, Kenya. West Indian J Mar Sci. 5(2):153-162. doi:10.4314/wiojms.v5i2.28507.

Kang JH, Lee YG, Lee KY, Cha SM, Cho KH, Lee YS, Ki SJ, Yoon IH, Kim KW, Kim JH. 2009. Factors affecting metal exchange between sediment and water in an estuarine 
reservoir: A spatial and seasonal observation. J Environ Manage. 11(11):2058-2067. doi:10.1039/b910526c.

Kolibongso D, Prartono T, Arman A. 2017. Trace metals distribution in aediment fractions of Karimata Strait, Indonesia. ILMU KELAUTAN: Indones J Mar Sci. 22(4):174. doi:10.14710/ik.ijms.22.4.174-184.

Li L, Zhen X, Wang X, Ren Y, Hu L, Bai Y, Liu J, Shi X. 2020. Benthic trace metal fluxes in a heavily contaminated bay in China: Does the sediment become a source of metals to the water column? Environ Pollut. 257:113494. doi:10.1016/j.envpol.2019.113494.

Little SH, Vance D, Walker-Brown C, Landing WM. 2014. The oceanic mass balance of copper and zinc isotopes, investigated by analysis of their inputs, and outputs to ferromanganese oxide sediments. Geochim Cosmochim Acta. 125:673-693. doi:10.1016/j.gca.2013.0 7.046 .

Liu B, Zhang W, Chi G. 2019. Distribution and risk assessment of heavy metals in sediment from Bohai Bay, China. Minerals. 9(2):111. doi:10.3390/min9020111.

Ni Z, Zhang L, Yu S, Jiang Z, Zhang J, Wu Y, Zhao C, Liu S, Zhou C, Huang X. 2017. The porewater nutrient and heavy metal characteristics in sediment cores and their benthic fluxes in Daya Bay, South China. Mar Pollut Bull. 124(1):547-554. doi:10.1016/j.marpolbul.2017.07.069.

Ololade I, Lajide L, Ololade O, Adeyemi O. 2011. Metal partitioning in sediment pore water from the Ondo coastal region, Nigeria. Toxicol Environ Chem. 93(6):1098-1110. doi:10.1080/02772248.2011.575784.

Pohl C, Löffler A, Hennings U. 2004. A sediment trap flux study for trace metals under seasonal aspects in the stratified Baltic Sea (Gotland Basin; 57¹9.20'N; $20^{\circ} 03$. 00'E). Mar Chem. 84(3-4):143-160. doi:10.1016/j.marc hem.2003.07.002.

Point D, Monperrus M, Tessier E, Amouroux D, Chauvaud L, Thouzeau G, Jean F, Amice E, Grall J, Leynaert A, Clavier J, Donard OFX. 2007. Biological control of trace metal and organometal benthic fluxes in a eutrophic lagoon (Thau Lagoon, Mediterranean Sea, France). Estuarine Coastal Shelf Sci. 72(3):457-471. doi:10.1016/j.ecss.200 6.11.013.

Riedel GF, Sanders JG, Osman RW. 1997. Biogeochemical control on the flux of trace elements from estuarine sediments: Water column oxygen concentrations and benthic infauna. Estuarine Coastal Shelf Sci. 44(1):2338. doi:10.1006/ecss.1996.0114.

Rigaud S, Radakovitch O, Couture RM, Deflandre B, Cossa D, Garnier C, Garnier JM. 2013. Mobility and fluxes of trace elements and nutrients at the sediment-water interface of a lagoon under contrasting water column oxygenation conditions. Appl Geochem. 31:35-51. doi: 10.1016/j.apgeochem.2012.12.003.

Riyadi AS, Itai T, Isobe T, Ilyas M, Sudaryanto A, Setiawan IE, Takahashi S, Tanabe S. 2012. Spatial profile of trace elements in marine sediments from Jakarta Bay, Indonesia. In: Kawaguchi M, Misaki K, Sato H, Yokokawa T, Itai T, Nguyen TM, Ono J, Tanabe S, editors. Interdisciplinary studies on environmental chemistry-environmental pollution and ecotoxicology. Tokyo: TERRAPUB. p. 141150.

Roth F, Wild C, Carvalho S, Rädecker N, Voolstra CR, Kürten B, Anlauf H, El-Khaled YC, Carolan R, Jones BH. 2019. An in situ approach for measuring biogeochemical fluxes in structurally complex benthic communities. Methods Ecol Evol. 10(5):712-725. doi:10.1111/2041-210X.13151.
Sabé R, Rauret G. 2004. Challenges for achieving traceability of analytical measurements of heavy metals in environmental samples by isotopic dilution mass spectrometry. Trends Anal Chem. 23(3):273-280. doi:10.1016/SO 165-9936(04)00311-5.

Santos-Echeandia J, Prego R, Cobelo-García A, Millward GE. 2009. Porewater geochemistry in a Galician Ria (NW Iberian Peninsula): Implications for benthic fluxes of dissolved trace elements (Co, $\mathrm{Cu}, \mathrm{Ni}, \mathrm{Pb}, \mathrm{V}, \mathrm{Zn})$. Mar Chem. 117(1-4):77-87. doi:10.1016/j.marchem.2009.05. 001.

Shi X, Mason RP, Charette MA, Mazrui NM, Cai P. 2018. Mercury flux from salt marsh sediments: Insights from a comparison between 224Ra/228Th disequilibrium and core incubation methods. Geochim Cosmochim Acta. 222:569-583. doi:10.1016/j.gca.2017.10.033.

Siregar TH, Priyanto N, Putri AK, Rachmawati N, Triwibowo R, Dsikowitzky L, Schwarzbauer J. 2016. Spatial distribution and seasonal variation of the trace hazardous element contamination in Jakarta Bay, Indonesia. Mar Pollut Bull. 110(2):634-646. doi:10.1016/j.marpolbul.20 16.05.008.

Spagnoli F, Penna P, Giuliani G, Masini L, Martinotti V. 2019. The AMERIGO Lander and the Automatic Benthic Chamber (CBA): two new instruments to measure benthic fluxes of dissolved chemical species. Sensors. 19(11):2632. doi:10.3390/s19112632.

Viana P, Yin K, Rockne K. 2018. Comparison of direct benthic flux to ebullition-facilitated flux of polycyclic aromatic hydrocarbons and heavy metals measured in the field. J Soils Sediments. 18(4):1729-1742. doi:10.1007/s1 1368-017-1893-z.

Vieira LH, Achterberg EP, Scholten J, Beck AJ, Liebetrau V, Mills MM, Arrigo KR. 2019. Benthic fluxes of trace metals in the Chukchi Sea and their transport into the Arctic Ocean. Mar Chem. 208:43-55. doi:10.1016/j.marche m.2018.11.001.

Viollier E, Rabouille C, Apitz SE, Breuer E, Chaillou G, Dedieu K, Furukawa Y, Grenz C, Hall P, Janssen F, Morford JL, Poggiale JC, Roberts S, Shimmield T, Taillefert M, Tengberg A, Wenzhöfer F, Witte U. 2003. Benthic biogeochemistry: state of the art technologies and guidelines for the future of in situ survey. J Exp Mar Biol Ecol. 285-286:5-31. doi:10.1016/S0022-0981(02)00517 -8 .

Wang W, Wang WX. 2017. Trace metal behavior in sediments of Jiulong River Estuary and implication for benthic exchange fluxes. Environ Pollut. 225:598-609. doi: 10.1016/j.envpol.2017.03.028.

Widianarko B, Verweij RA, Van Gestel CA, Van Straalen NM. 2000. Spatial distribution of trace metals in sediments from urban streams of Semarang, Central Java, Indonesia. Ecotoxicol Environ Saf. 46(1):95-100. doi:10.1006/ eesa.1999.1878.

Zago C, Capodaglio G, Ceradini S, Ciceri G, Abelmoschi L, Soggia F, Cescon P, Scarponi G. 2000. Benthic fluxes of cadmium, lead, copper and nitrogen species in the northern Adriatic Sea in front of the River Po outflow, Italy. Sci Total Environ. 246(2-3):121-137. doi:10.1016/ S0048-9697(99)00421-0.

Zhu X, Shan B, Tang W, Li S, Rong N. 2016. Distributions, fluxes, and toxicities of heavy metals in sediment pore water from tributaries of the Ziya River system, northern China. Environ Sci Pollut Res. 23(6):5516-5526. doi: 10.1007/s11356-015-5709-7. 